\title{
Kneading behaviour and homogeneity of zirconia feedstocks for micro-injection molding
}

\author{
Rong-Yuan Wu, Wen-Cheng J. Wei* \\ Institute of Materials Science and Engineering, National Taiwan University, 1 Roosevelt Road Section 4, Taipei 106, Taiwan, ROC
}

Received 10 September 2003; received in revised form 28 November 2003; accepted 28 November 2003

Available online 17 April 2004

\begin{abstract}
This study used capillary rheometer, transmission optic microscopy (TOM) and torque rheometer to quantitatively analyze the homogeneity of zirconia feedstock and presents the report of the relationship between homogeneity and kneading parameters. The rheological indexes $\left(\alpha_{\text {stv }}\right.$, $H_{\mathrm{a}}$ and $H_{\mathrm{z}}$ ) of four feedstocks were determined by the capillary rheometer showing consistent results. The results of torque and kneading power input of the feedstocks showed consistent behavior with the microstructural parameter (dispersive index, $D_{\mathrm{s}}$ ). This indicated that the $D_{\mathrm{s}}$ $\left(=1-\phi_{\mathrm{a}}\right)$ could be used as a parameter for the improvement of the homogenous property of the feedstocks. The power consumption diagram (kneading power-Reynolds number, $N_{\mathrm{p}}-R e^{\prime}$ ) calculated by several torque parameters reveals the critical issues related to the homogeneity of the feedstocks.
\end{abstract}

(C) 2004 Elsevier Ltd. All rights reserved.

Keywords: $\mathrm{ZrO}_{2}$; Kneading; Homogeneity; Injection moulding

\section{Introduction}

The procedures of ceramic injection molding (CIM) include four steps: kneading process, injection molding, debinding, and sintering. ${ }^{1-3}$ The CIM technology offers the opportunity to make complex and near-net-shape of ceramic parts. The kneading process is an important step in ceramic injection molding. The kneading stress offered by a $\Sigma$-blade kneader is small, and generally not enough to break down the powder agglomerates in the ceramic feedstock. Especially, the agglomerates consisted of ultra-fine powder. The agglomerates are retained until sintering and become the fracture origin if the effective size of the defects is too large to withstand fracture stress. Evans et al. ${ }^{4}$ reported a result of zirconia, which was fractured in a defect size greater than $10 \mu \mathrm{m}$. The fracture strength is not affected, if the agglomerates are smaller than $10 \mu \mathrm{m}$.

Recently, the fundamental and application issues of nanotechnology and micro-electromechanical system (MEMS) have evoked the interest of the interesting to ceramists. The precision microinjection molding make the manufacturing

\footnotetext{
* Corresponding author.

E-mail address: wjwei@ccms.ntu.edu.tw (W.-C.J. Wei).
}

of small parts possible for many advanced applications. The powder size must be reduced to produce thin and complex parts. The nano powder tends to agglomerate due to van der Waal force. ${ }^{3}$ However, little attention for the kneading behavior of ceramic feedstock have been given in literature by using ultra-fine or nano powder. ${ }^{1-4,21,22}$

Kneader normally produces high shear stress for the mixing of highly solid loaded mixture. Kneading technique is widely used in the industries such as polymer blend, and food process. ${ }^{5-7}$ In the kneading process, power consumption index ${ }^{4,5}$ is an important parameter. It has been concluded that a power number-Reynolds number $\left(N_{\mathrm{p}}-R e\right)$ diagram can predict the degree of reaction mixture, but also be used as the index to design the kneading equipment. The $N_{\mathrm{p}}-R e$ values can be calculated from torque and rotor speed of experimental kneader. The $N_{\mathrm{p}}-R e$ predicts plastic flow behavior of the feedstocks and gives the index of scaling up for designing the kneader.

Nagata ${ }^{8}$ modified the experimental produce of the mixing of a low solid content mixture from the work of MetznerOtto. The work described the kneading behavior of a high powder solid content. The calculation of power consumption diagram and kneading condition were improved for the mixing effect. Firstly, it can get apparent viscosity and shear stress of high solid loading mixture from Casson 
equation. ${ }^{8,9}$ Kamiwano et al. ${ }^{9}$ suggested that Nagata's paper dealt with mixture in the range of solid content lower than 40 vol.\%. The reason is that co-axial rheometer can not measure the viscosity of high solid content mixture. Therefore, Kamiwano et al. ${ }^{11}$ uses Casson model to get shear stress and apparent viscosity of high solid content mixture. Finally, the power number and Reynolds number can be calculated by viscosity parameters from Casson equation.

Kamiwano et al. ${ }^{11}$ kneaded the mixture of clay and silicone oil to knead. The results show that Reynolds number is relative to apparent viscosity. $N_{\mathrm{p}}{ }^{\prime}-R e^{\prime}$ diagram does not depend on the kinds of powder and scale-up ratio of kneaders. However, literature hardly reports $N_{\mathrm{p}}{ }^{\prime}-R e^{\prime}$ diagram to control or monitor the ceramic feedstock properties of kneading process.

Two subjects have been investigated. First, the properties of Mg-PSZ (magnesium-partially stabilized zirconia) and 3Y-TZP (yttria-tetragonal zirconia polycrystals) feedstock can be quantified to show the homogeneity of feedstocks. The indexes of rheological behavior and dispersive index of microstructure are firstly quantitatively correlated to the homogenous property of feedstock. Secondly, the torque behavior of Mg-PSZ and 3Y-TZP feedstocks are measured to get $N_{\mathrm{p}}{ }^{\prime}-R e^{\prime}$ power consumption diagram. The relationship between fraction of agglomerate and power of kneader is observed. Therefore, the power consumption behavior of kneading process is monitored to improve the homogeneity of the feedstocks.

\section{Analysis of homogeneity and kneading feedstock}

\subsection{Quantitative analysis of feedstocks}

The quantitative analysis of the homogeneity of feedstock reported in literature can be divided into two categories, rheological and microstructural, as shown in Table 1.

\subsubsection{Rheological method}

According to literature, most of the research works used rheology behavior of feedstocks showing homogeneity properties. ${ }^{1-3,12-14}$ Those desired rheological properties include minimum viscosity $(\eta)$, low activity energy $(E)$, consistent flow index $(n)$, and low yielding stress $(K)$. Li et al. ${ }^{15}$ stated that the ideal homogenous feedstock showed the properties of low viscosity, low flow index and low activity energy. The calculated moldability index is represented as shown in Table 1.

By the way, the curve of capillary force-time shows homogenous properties at constant shear strain. The feedstocks predict best homogenous feedstock due to the smaller change of force-curve. The change of curve can be quantitative analysis by statistical method to show homogenous properties as shown in Table 1.

\subsubsection{Microstructure}

The dispersive index $\left(D_{\mathrm{S}}\right)$ is defined as the volumetric fraction of the powder in agglomerate that appeared on the feedstock microstructure. The definition of dispersive index is shown in Table $1 .^{16}$ The dispersive index $\left(1-\phi_{\mathrm{a}}\right)$ varies from 0 , which all particles remain in the form of agglomerations, to 1 , which no agglomeration exists in the feedstock. The detail quantitative method is presented in Section 3.

\subsection{Power consumption analysis of non-Newtonian fluid}

\subsubsection{Non-Newtonian fluid}

The relationship between power number and Reynolds number for a mixing conducted in a vessel is given as follows: ${ }^{8-11}$

$N_{\mathrm{p}} \times \operatorname{Re}=\beta$

where $N_{\mathrm{p}}$ is the power number $\left(=P / \rho N^{3} d^{5}\right), \operatorname{Re}$ is the Reynolds number $\left(=\rho N d^{2} / \mu_{\mathrm{a}}\right), P$ is power $(=2 \pi N T(\mathrm{~W}))$, $\mu_{\mathrm{a}}$ is the apparent viscosity of non-Newtonian fluid (Pas), $\beta$ is the constant that is relative to blade diameter and vessel size, $d$ is blade diameter $(\mathrm{m}), \rho$ is true density of feedstock $\left(\mathrm{kg} / \mathrm{m}^{3}\right), T$ is torque $(\mathrm{Nm})$, and $N$ is blade speed $\left(\mathrm{s}^{-1}\right)$.

A rheological equation for fluids with a yielding stress, such as Casson model, is adopted for plastic feedstocks. The shear stress and apparent viscosity of feedstock can be correlated by Casson model. ${ }^{17,18,23,24}$ Moreover, Kamiwano et al. ${ }^{11}$ used the Casson model to get the relationship between shear stress and blade speed in the mixing vessel. The Casson equation is given as follows:

$\tau^{1 / 2}=\tau_{\mathrm{c}}{ }^{1 / 2}+\left(\mu_{\mathrm{c}} \dot{\gamma}\right)^{1 / 2}$

where $\mu_{\mathrm{c}}$ is the Casson viscosity, $\tau_{\mathrm{c}}$ is the Casson yield strength, $\tau$ is the yield strength, and $\dot{\gamma}$ is the shear rate.

Eq. (2) is transformed into Eq. (3) to get viscosity of feedstock as a function:

$\mu_{\mathrm{a}}^{1 / 2}=\left(\frac{\tau_{\mathrm{c}}}{\dot{\gamma}}\right)^{1 / 2}+\mu_{\mathrm{c}}{ }^{1 / 2}$

where $\mu_{\mathrm{a}}$ is the apparent viscosity (Pa s).

Metzner and Otto ${ }^{19}$ proposed that the mean average shear rate $\left(\dot{\gamma}_{a v}\right)$ for non-Newtonian fluid in a mixing vessel is proportional to rotational speeds. The relationship shows:

$\dot{\gamma}_{\mathrm{av}}=B \times N$

where $B$ is the specific equipment factor, $\dot{\gamma}_{\text {av }}$ is the average shear stress, and $N$ is the rotational speed.

Nagata observed that laminar flow does take place for non-Newtonian feedstock mixing in a vessel. Substituting Eqs. (1) and (4) to Eq. (3), we get:

$$
\left(\frac{2 \pi T}{d^{3} \beta}\right)^{1 / 2}=\left(\frac{\tau_{\mathrm{c}}}{B}\right)^{1 / 2}+\left(\mu_{\mathrm{c}} N\right)^{1 / 2}
$$

The $\tau_{\mathrm{c}} / B$ means the ratio of yield shear stress $\left(\tau_{\mathrm{c}}\right)$ to specific equipment factor $(B)$. Casson plastic viscosity $\left(\mu_{\mathrm{c}}\right)$ and 
Table 1

Methods for the determination of homogeneity of feedstocks

\begin{tabular}{|c|c|c|c|c|}
\hline Category & Properties & Equation & Homogenous state & Reference \\
\hline \multirow[t]{6}{*}{ Rheology } & Viscosity (power law) $(\eta)$ & $\eta=\frac{\tau}{\dot{\gamma}}$ & Low & German and Bose \\
\hline & Activation energy $(E)$ & $\eta=\eta_{0} \exp \left(\frac{E}{R T}\right)$ & Low & Zhang and Evans ${ }^{3}$ \\
\hline & Flow index $(n)$ & $\eta=K \dot{\gamma}^{n-1} \quad \ln \eta-\ln K=(n-1) \ln \dot{\gamma}$ & Variation & Wei et al. ${ }^{13}$ \\
\hline & Yield stress $(K)$ & & Low & German and Bose \\
\hline & Moldability index $\left(\alpha_{\mathrm{stv}}\right)$ & $\alpha_{\mathrm{stv}}=\frac{1}{\eta_{0}}\left(\frac{R|n-1|}{E}\right)$ & Large & Li et al. ${ }^{15}$ \\
\hline & Homogenous index $\left(H_{\mathrm{a}}, H_{\mathrm{z}}\right)$ & $H_{\mathrm{a}}=\frac{1}{l} \int_{0}^{l}|f(x)| \mathrm{d} x \quad H_{\mathrm{z}}=\frac{\left(R_{1}+R_{3}+R_{5}+R_{7}+R_{9}\right)-\left(R_{2}+R_{4}+R_{6}+R_{8}+R_{10}\right)}{5}$ & Small & Wei et al. (2001) \\
\hline Microstructure & Dispersive index $\left(1-\phi_{\mathrm{a}}\right)$ & Dispersive index $=1-\phi_{\mathrm{a}}, \phi_{\mathrm{a}}=\frac{\pi}{4 A \phi} \sum_{i=1}^{N} d_{i}^{2} n_{i}$ & Near 1 & Suetsugu $^{16}$ \\
\hline
\end{tabular}

$\tau$, shear stress; $\gamma$, shear rate; $R$, constant $(8.3144 \mathrm{~J} / \mathrm{k} \mathrm{mol}) ; \eta_{0}$, relative viscosity; $f(x)$, capillary force; $l$, time; $R_{1}, R_{3}, R_{5}, \ldots$, maximum capillary force; $R_{2}, R_{4}, \mathrm{R}_{6}, \ldots$, minimum capillary force; $\phi_{2}$ agglomerate fraction; $A$, total area; $\phi$, solid loading; $d_{i}$, agglomerate diameter; and $n_{i}$, agglomerate number. 
$\tau_{\mathrm{c}} / B$ can be measured from the slope and the intercept of the straight line, respectively, from the plot of $\left(2 \pi T / d^{3} \beta\right)^{1 / 2}$ versus $N^{1 / 2}$. On the other hand, the apparent viscosity can be given by the following equation if $B_{\text {ic }}=\tau_{\mathrm{c}} / B \mu_{\mathrm{c}} N$ and from Eqs. (3) and (4):

$\mu_{\mathrm{a}}=\mu_{\mathrm{c}}\left(1+B_{\mathrm{ic}}{ }^{1 / 2}\right)^{2}$

where $B_{\text {ic }}$ is modified Bingham number. Additionally, $R e^{\prime}$ in Eq. (1) can be expressed as follows:

$R e^{\prime}=\frac{\rho N d^{2}}{\mu_{\mathrm{c}}\left(1+B_{\mathrm{ic}}{ }^{1 / 2}\right)^{2}}=\frac{R e}{\left(1+B_{\mathrm{ic}}{ }^{1 / 2}\right)^{2}}$,

$R e=\frac{\rho N d^{2}}{\mu_{\mathrm{c}}}$

The modified relationship between power number and Reynolds number of a non-Newtonian feedstock is given by the following equation:

$N_{\mathrm{p}} \times \frac{R e}{\left(1+B_{\mathrm{ic}}{ }^{1 / 2}\right)^{2}}=N_{\mathrm{p}} \times \operatorname{Re}^{\prime}=\beta$

\section{Experimental procedure}

\subsection{Materials}

The raw materials used in this study include Mg-PSZ ${ }^{20}$ powder (Z-Tech., USA) and 3Y-TZP (Teamcera, Taiwan, ROC) with specific BET surface area $14 \mathrm{~m}^{2} / \mathrm{g}$. The binders for the feedstock include polypropylene (PP, Formosa Plastic, Taiwan), low density polyethylene (LDPE, USIFENA208, Taiwan), paraffin wax (Nippon Serio, Japan), and a surfactant with ester function group. According to previous results ${ }^{20}$ of torque rheometer, the solid content of feedstocks was selected at $54 \mathrm{vol} . \%$. The polymeric ingredients were in a ratio of PP:PW:surfactant $=25: 70: 5$. The material properties are shown in Table 2.

\subsection{Kneading}

Kneading equipment with twin $\Sigma$-type blades (Ray-E Manufacture Co., Tainan, Taiwan) was used and operated at a rate of $35 \mathrm{rpm}$. The kneading conditions of Mg-PSZ and
3Y-TZP feedstock was the same as that used in previous study. ${ }^{12,20}$

\subsection{Capillary rheometry}

A capillary rheometer (Rosand, RH7, UK) was used to determine the pushing force exerted on the melting feedstocks during test. The test temperature was at $170 \pm 1{ }^{\circ} \mathrm{C}$. The range of shear rate is from 150 to $1500 \mathrm{~s}^{-1}$. The capillary diameter is $1.00 \mathrm{~mm}$. The curve of capillary force-time was to measure homogeneity of feedstock at $500 \mathrm{~s}^{-1}$.

\subsection{Torque rheometry}

Torque rheometry was self-assembled. ${ }^{12}$ A twin-blade kneader with a torque transducer and signal amplifier were used. The amplifier transformed the measured torque to an electric signal which could be recorded. The operating conditions used blade speed $(21,30$, or $55 \mathrm{rpm})$ and kneading temperature $\left(130,150\right.$, or $\left.170^{\circ} \mathrm{C}\right)$.

\subsection{Optic microscopy and quantitative analysis of microstructure}

The feedstock was melted and pressed by glass plates to a thin film with a thickness of about $10 \mu \mathrm{m}$. The powder agglomeration of a feedstock can be by optic microscopy (Nikon HFX-DX, Japan). The contrast of powder agglomerate shows black due to the effect of light scattering of the transmission light. The resolution of the $\mathrm{OM}$ is better than $2 \mu \mathrm{m}$. The dispersive index $\left(D_{\mathrm{S}}\right)$ is defined as a ratio of black area which shows at least $10 \mu \mathrm{m}$ diameter, to total area.

\subsection{Power consumption diagram}

Silicone oils were used as Newtonian fluid. Viscosities of STD 100 (Brookfield, USA) and STD 380 (Brookfield, USA) are 100.48 and $380 \mathrm{~Pa}$ s, respectively. Based on Eq. (1) in Fig. 1 of the flow chart, the value of $\beta$ for kneader is obtained. Then, controlling the kneading temperature and blade speed, the torque value measured by torque rheometer can be used to estimate power input $(P)$ into feedstock. According to the plot of $\left(2 \pi T / d^{3} \beta\right)^{1 / 2}$ and $N^{1 / 2}$, the $N_{\mathrm{p}}-R e^{\prime}$

Table 2

Powder and polymeric binders used in this study

\begin{tabular}{lllll}
\hline Powder & Phase & Density $\left(\mathrm{g} / \mathrm{cm}^{3}\right)$ & Supplier & Country \\
\hline Mg-PSZ & $m+c$ & 5.9 & Z-tech Co. & USA \\
3Y-TZP & $t$ & 6.03 & Teamcera & Taiwan \\
Binder & $T_{\mathrm{m}}\left({ }^{\circ} \mathrm{C}\right)$ & Density $\left(\mathrm{g} / \mathrm{cm}^{3}\right)$ & Molecular weight & Supplier, batch number \\
\hline PP & 170 & 0.903 & $10000-15000$ & TCC-P366(5), Taiwan \\
LDPE & 150 & 0.916 & $40000-45000$ & USIFE-NA208, Taiwan \\
PW & 68 & 0.918 & 7178 & Nippon Serio, Japan \\
SA & 71.9 & 0.962 & 910 & Nacalai Tesque Inc., Japan \\
F1 & - & 0.96 & & ICI, England, UK \\
\hline
\end{tabular}




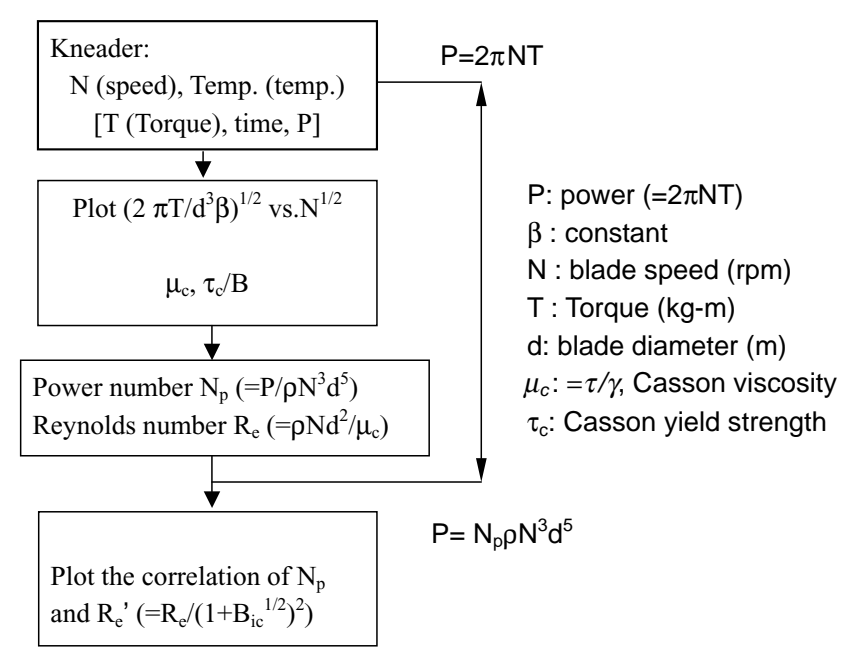

Fig. 1. Flowchart to calculate each parameter and the step for the plotting of $N_{\mathrm{p}}-\operatorname{Re}^{\prime}$ diagram.

power consumption diagram is plotted. A flow chart showing the steps to obtain power consumption diagram is shown in Fig. 1.

\section{Results and discussion}

\subsection{Quantitative analysis of feedstock homogeneity}

Several rheological indexes shown in the previous (Table 1) are capable of describing the consistency of the property of feedstocks. The minimal viscosity, low flow activity energy, consistent flow index and low yield stress of feedstock were used to reveal the homogeneity. ${ }^{1-3}$ Fig. 2 shows the relationship between apparent viscosity and

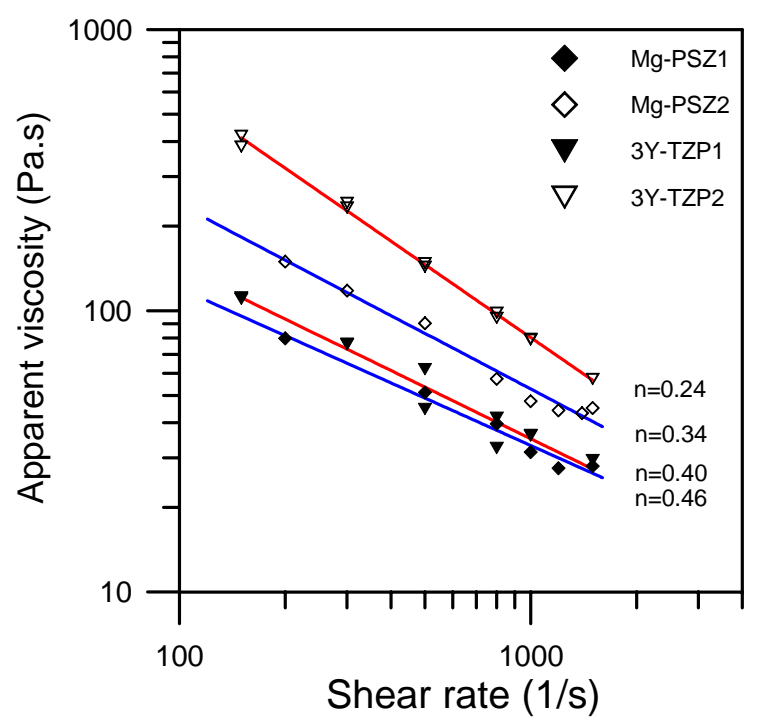

Fig. 2. Relationship of the viscosity of four zirconia feedstocks to shear rate tested at $170^{\circ} \mathrm{C}$.
Table 3

Quantitative analysis of homogeneity by different methods for four zirconia feedstocks

\begin{tabular}{lcccc}
\hline Properties & Mg-PSZ1 & Mg-PSZ2 & 3Y-TZP1 & 3Y-TZP2 \\
\hline$\eta$ & 35 & 61 & 38 & 80 \\
$E$ & 32 & 34 & 14 & 12 \\
$n$ & 0.46 & 0.34 & 0.4 & 0.24 \\
$K$ & 1580 & 4900 & 2359 & 30978 \\
$\alpha_{\text {stv }}$ & 8.6 & 17.2 & 23.8 & 73.9 \\
$H_{\mathrm{a}}$ & 23 & 18 & 12 & 1 \\
$H_{\mathrm{Z}}$ & 24 & 22 & 20 & 1 \\
\hline
\end{tabular}

shear rate of zirconia feedstocks. The apparent viscosity of Mg-PSZ1 feedstock is less than $100 \mathrm{~Pa}$ s between 150 and $1500 \mathrm{~s}^{-1}$. The flow index is 0.46 . The viscosity of Mg-PSZ2 is higher than Mg-PSZ1 but the yield stress of Mg-PSZ1 is lower than Mg-PSZ2.

The apparent viscosity of 3Y-TZP1 feedstock is less than $100 \mathrm{~Pa}$ s. The flow index is 0.40 . The viscosity of $3 \mathrm{Y}-\mathrm{TZP} 2$ is higher than $3 \mathrm{Y}-\mathrm{TZP} 1$. The yield stress of $3 \mathrm{Y}-\mathrm{TZP} 1$ is higher than 3Y-TZP2.

Lin and German ${ }^{2}$ proposed that the $\mathrm{Al}_{2} \mathrm{O}_{3}$ feedstock contained less agglomerate with the properties of low viscosity and yield stress. According to our previous report, ${ }^{13}$ the $\mathrm{Al}_{2} \mathrm{O}_{3}$ test bars made by the feedstock showed best mechanical properties among the injection molding samples. The rheological indexes of the feedstocks are hardly differentiated at testing temperatures. However, previous results on various properties $\eta, K, E$ and $n$ in Table 3 , are not consistent in showing the homogeneity of feedstocks.

Li et al. ${ }^{15}$ used the quantitative moldability index $\left(\alpha_{\text {stv }}\right)$ to show the homogeneity of feedstocks. The parameter consisted of viscosity, flow index and flow activity energy, as shown in Table 3. The larger moldability index $\left(\alpha_{\text {stv }}\right)$ shows better homogeneity due to low viscosity and activity energy. If we use similar analysis calculation, the moldability index of Mg-PSZ1 is 8.6, which is smaller than 17.2 of Mg-PSZ2. The moldability index of 3Y-TZP2 is greater than 3Y-TZP1. The $\alpha_{\text {stv }}$ value increases with increasing feedstock homogeneity. Although the rheological results of $\eta, E$ and $K$ given in literature ${ }^{1-3,12-14}$ are inconsistent to show the homogeneity of various zirconia feedstock (Table 3 ), there is agreement that the other parameter(s) should be able to show the feedstock homogeneity.

German and Bose ${ }^{1}$ determined feedstock homogeneity from the data variation of capillary force-time $(F-t)$ relationship shown during capillary rheological test. Pressure fluctuation through a small capillary can reveal the homogenous character of feedstocks. The fluctuation in the force-time curve indicates the positions of low or high pressure representing binder-rich or solid-rich feedstock, respectively. Fig. 3 shows the curve of extruded capillary force versus testing time for Mg-PSZ1, Mg-PSZ2, 3Y-TZP1 and 3Y-TZP2 feedstocks. The curve variation of Mg-PSZ2 is smaller than that of Mg-PSZ1. Similarly, the curve variation of 3Y-TZP1 is greater than that of 3Y-TZP2. Mg-PSZ2 and 3Y-TZP2 


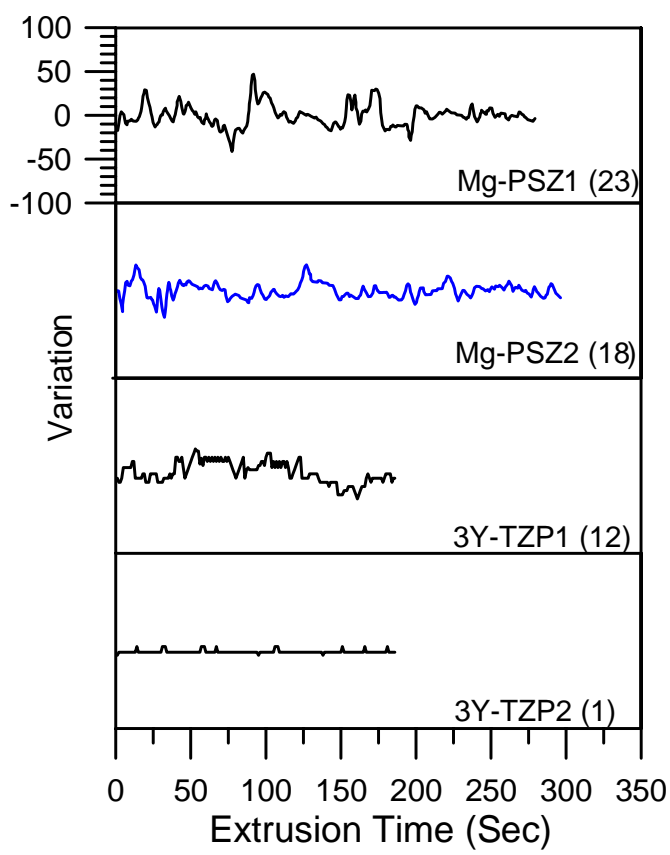

Fig. 3. Capillary force plotted against extrusion time of the zirconia feedstock.

feedstocks show respectively less fluctuation in composition than the others.

Table 3 also indicates that $H_{\mathrm{a}}$ and $H_{\mathrm{Z}}$ of Mg-PSZ2 or 3Y-TZP2 are smaller than that of Mg-PSZ1 or 3Y-TZP1, respectively. The quantitative indexes of $\alpha_{\mathrm{stv}}, H_{\mathrm{a}}$ and $H_{\mathrm{Z}}$ are consistent that may be used to representing feedstock homogeneity.

The powder agglomeration in feedstocks can be observed by transmission optic microscopy. The dispersive index shows the degree of homogeneity by quantitative analysis. Fig. 4 is the microstructure of 3Y-TZP2 feedstock. The images contained power agglomerates in sizes $\leq 100 \mu \mathrm{m}$. Fig. $4 \mathrm{~b}$ reveals the agglomerates which are equi-axial spraydrying granules $(<20 \mu \mathrm{m})$ or broken granules $(>50 \mu \mathrm{m})$. The dispersive index $\left(D_{\mathrm{s}}\right)$ of the feedstock is measured to be 0.81 . The $19 \%$ in volume of the agglomerates cannot be broken by the $\Sigma$-blade kneader. The shear stress produced by kneader is smaller than the deformation stress of smaller spray-drying granules. However, the fracture strength of sintering body is a function of the reverse of square root of defect dimension $(1 / \sqrt{D})$. The maximal defect could be the fracture origin due to the agglomerate leftover in the kneading process.

The sintering parts are measured for debinding and sintering process, as shown in Table 4 . The literatures ${ }^{1-3}$ show

Table 4

Length $(L)$ and standard deviation $(\sigma)$ of sintering bodies made of four zirconia feedstocks

\begin{tabular}{lllll}
\hline & Mg-PSZ1 & Mg-PSZ2 & 3Y-TZP1 & 3Y-TZP2 \\
\hline$L(\mathrm{~mm})$ & $40.79 \pm 0.03$ & $40.24 \pm 0.01$ & $39.57 \pm 0.07$ & $38.36 \pm 0.01$ \\
$\pm 1 \sigma$ & & & & \\
\hline
\end{tabular}

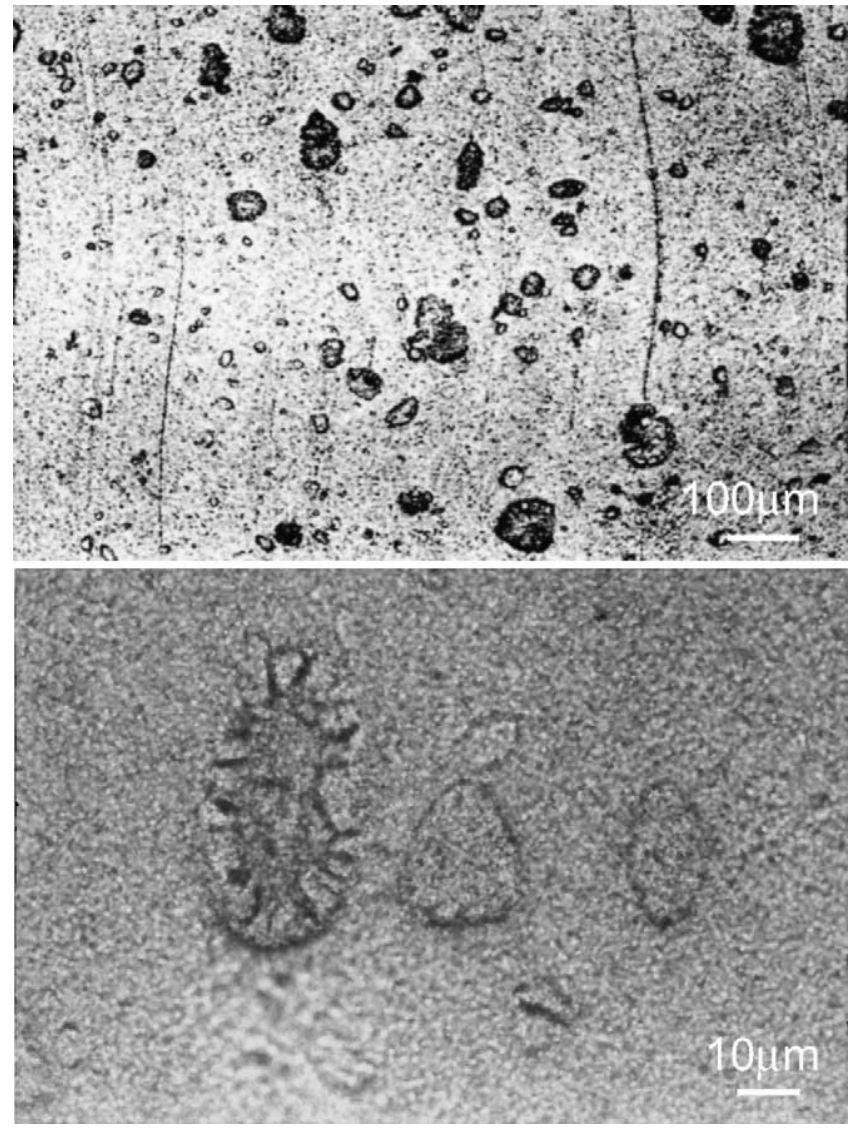

Fig. 4. Optical micrographs in different magnifications revealing the morphologies of the agglomerates in 3 Y-TZP2 feedstocks kneaded by $\Sigma$-blade kneader.

that better homogeneity of feedstock is as well as the dimensional stability of part. The homogeneity of Mg-PSZ2 $\left(H_{\mathrm{a}, \mathrm{Mg}-\mathrm{PSZ} 2}<H_{\mathrm{a}, \mathrm{Mg}-\mathrm{PSZ} 1}\right)$ and 3Y-TZP2 $\left(H_{\mathrm{a}, 3 \mathrm{Y}-\mathrm{TZP} 2<}<\right.$ $\left.H_{\mathrm{a}, 3 \mathrm{Y}-\mathrm{TZP} 1}\right)$ feedstock are better than the others and the parts of dimensional stability are less than $0.1 \%$ standard deviation percent.

\subsection{Homogeneity and power consumption diagram}

Laminar flow is usually associated with high viscosity liquid, which may be either Newtonian or non-Newtonian. From a practical point of view, power consumption is one of the important parameters in the design of mixing vessels. Because of very different flow patterns and mixing mechanisms involved, it is convenient to consider power consumption instead of the distribution of stress-strain distribution in the vessel.

The power consumption properties of feedstock were measured by the torque rheometer. The feedstock is assumed to be a laminar flow showing non-Newtonian behavior. The kneaders show only one equipment factor $(\beta)$ if they have same geometry but different in size. Therefore, it assumes that $\beta$ of Newtonian flow is equal to $\beta$ of non-Newtonian flow. ${ }^{10}$ According to the results of Kamiwano et al. the 


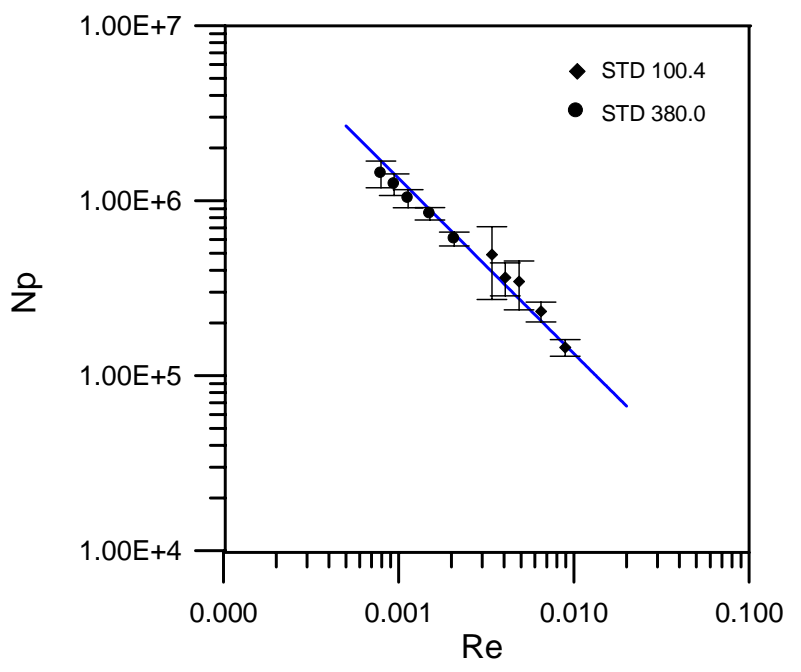

Fig. 5. $N_{\mathrm{p}}-R e$ correlation diagram of two Newtonian fluids.

equipment factor $(\beta)$ of KT2 blade is $2262 .{ }^{11}$ Two standard of viscous fluids are Newtonian fluids. Their $N_{\mathrm{p}}-R e$ properties are shown in Fig. 5. The $\beta$ value of our mixing vessel determined by two standard fluids is 1340 .

The torque data obtained by Casson model reveals rheological behavior of the feedstocks in the vessel. The feedstocks included polypropylene (PP), low density polyethylene (LDPE), Mg-PSZ1, Mg-PSZ2, 3Y-TZP1 and 3Y-TZP2. Fig. 6 shows the relationships between $\left(2 \pi T / d^{3} \beta\right)^{1 / 2}$ and $N^{1 / 2}$ which are calculated from Eq. (5) at $170^{\circ} \mathrm{C}$. The slope and intercept of the curves are $\tau_{\mathrm{c}} / B$ and $\mu_{\mathrm{c}}$, respectively.

The kneader produced different shear force and shear rate due to the geometry of blade. Kamiwano et al. ${ }^{11}$ concluded the experiment results of blades in different geometry. The gap between kneader blade and vessel reduces with decreas-

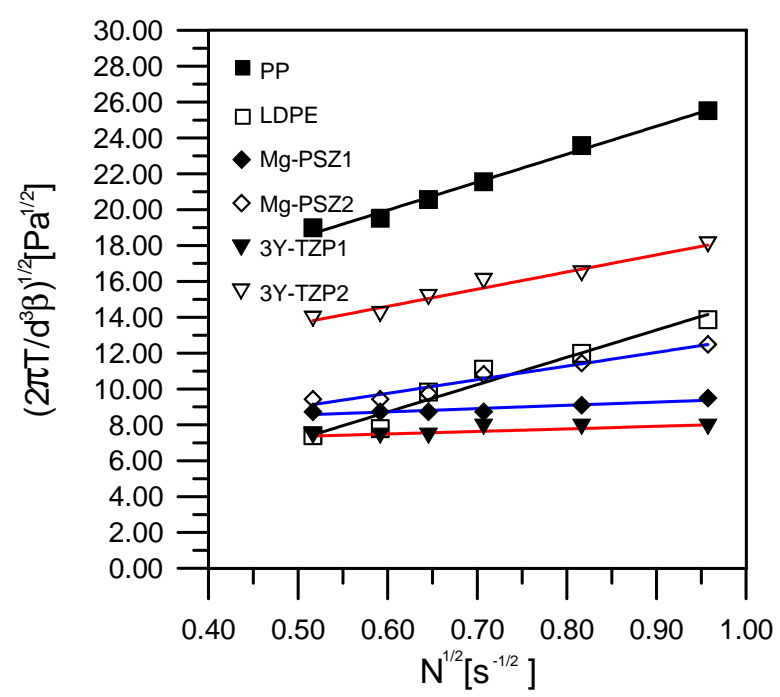

Fig. 6. Relationship between $\left(2 \pi T / d^{3} \beta\right)^{1 / 2}$ and $N^{1 / 2}$ for PP, LDPE, Mg-PSZ, and 3Y-TZP feedstocks at $170^{\circ} \mathrm{C}$.

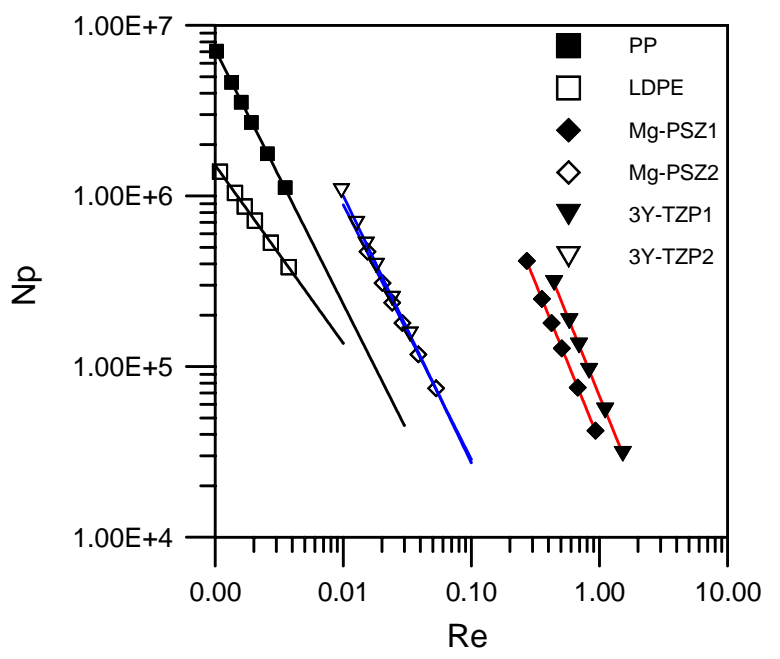

Fig. 7. $N_{\mathrm{p}}$ vs. $R e$ based on Casson viscosity for PP, LDPE, Mg-PSZ, and 3Y-TZP feedstocks.

ing $\tau_{\mathrm{c}} / B$. The $\tau_{\mathrm{c}} / B$ of polypropylene and Casson viscosity are higher than the others. The $\tau_{\mathrm{c}} / B$ values of Mg-PSZ2 and 3Y-TZP2 feedstocks are higher than Mg-PSZ1 and 3YTZP1. The Casson viscosity $\left(\mu_{\mathrm{c}}\right)$ of Mg-PSZ2 and 3Y-TZP2 are higher than Mg-PSZ1 and 3Y-TZP1. It implies that the shear stress of kneader input to Mg-PSZ2 and 3Y-TZP2 feedstocks are greater than that into the Mg-PSZ1 and 3YTZP1.

According to the previous parameter of $\tau_{\mathrm{c}} / B$ and $\mu_{\mathrm{a}}$ it can be calculated to $N_{\mathrm{p}}$ and $R e$. The values of $N_{\mathrm{p}}$ and $R e$ can be calculated from $\tau_{\mathrm{c}} / B, \mu_{\mathrm{c}}$, and $\mu_{\mathrm{a}}$, and are shown in Fig. 7. The complexity of flow in mixers of specific type puts the dimensional analysis being an exclusive tool for the correlation of used parameters. The dimensional analysis yields the Reynolds number to be dimensionless. The dimensional analysis of power number will show the power (W) in dimensionless. It means the power involved the motion blades of specific geometry inputs the power into the feedstock.

Reynolds number of LDPE is reduced more significant than the others PP and Mg-PSZ2. The power consumption diagram of each feedstocks show its $N_{\mathrm{p}}-R e$ curves in a vessel of same geometry. It is inconsistent to the result that Nagata ${ }^{10}$ shows that the geometry of single blade has only one equipment factor, and power consumption curve. The blade speed of kneader increases with power number, and the Reynolds number reduces. The power numbers of $\mathrm{Mg}$ PSZ1 and 3Y-TZP1 are greater than Mg-PSZ2 and 3Y-TZP2 based on same $R e^{\prime}$ and $N$. The result represents that the inputting power to Mg-PSZ1 and 3Y-TZP1 feedstocks are greater than that of Mg-PSZ2 and 3Y-TZP2 from kneader. Part of the reason is that the melting point of 3Y-TZP1 feedstock $\left(100^{\circ} \mathrm{C}\right)$ is lower than $3 \mathrm{Y}$-TZP2 $\left(140^{\circ} \mathrm{C}\right){ }^{20}$ Therefore, as the kneader inputs same power to feedstocks, the Reynolds number of Mg-PSZ1 and 3Y-TZP1 are reduced quicker than Mg-PSZ2 and 3Y-TZP2. 


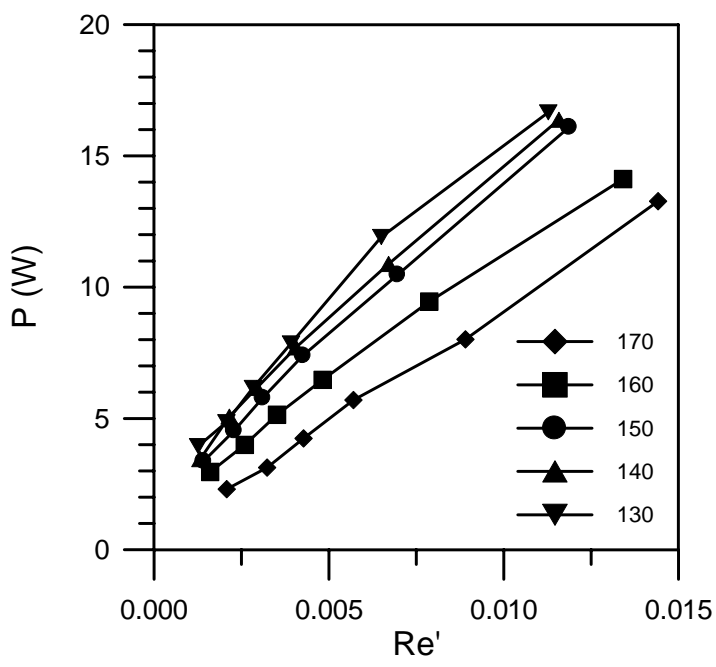

Fig. 8. Power-Reynolds number-temperature (P-R-T) diagram for $3 \mathrm{Y}-\mathrm{TZP} 2$ feedstock tested at different temperatures $\left({ }^{\circ} \mathrm{C}\right)$.

Fig. 8 shows the relationships amongst input power $(P)$, modified Reynolds number $\left(R e^{\prime}\right)$ and kneading temperature $(\mathrm{P}-\mathrm{R}-\mathrm{T})$ of $3 \mathrm{Y}-\mathrm{TZP}$. Because the $\mathrm{P}-\mathrm{R}-\mathrm{T}$ relationship of Mg-PSZ2 is similar to that of 3Y-TZP2, thus, only the behavior of $3 \mathrm{Y}-\mathrm{TZP} 2$ feedstock is discussed. Previous data show that the blade speed increases with increasing Reynolds number and input power in isothermal condition. Secondly, the kneading temperature increases with decreasing input energy.

The interest in power consumption during kneading process stems not only from economic considerations but also from indicative of torque change in the flow pattern in the vessel. Also power consumption measurements are frequently used to characterize the feedstock rheology in a mixing system. From previous data of initial $D_{\mathrm{s}}$ the $3 \mathrm{Y}$ TZP2 feedstock will be observed $19 \%$ of agglomerate by transmission optic microscopy. The three kinds of different kneading power are selected to improve the homogeneity of feedstock.

The kneading power is used to break down the agglomerate of feedstock. The relationship between the agglomerate state of feedstock and kneading power can be an indication of energy intake of feedstocks. The conditions of kneading power are controlled by the kneading temperature, blade speed and capability of energy intake of a feedstock. Three kneading conditions of 3Y-TZP were exercised, 170, 150 and $130^{\circ} \mathrm{C}$ for $60 \mathrm{~min}$. The slope of power curve of $150^{\circ} \mathrm{C}$ is larger than the others according to Fig. 8 data. The $130^{\circ} \mathrm{C}$ is the smallest slope of power curve. The agglomerate state of feedstock is analyzed by the quantitative technique of dispersive index $\left(D_{\mathrm{s}}\right)$, which reveals the fraction of powder agglomerate in feedstock. The initial $D_{\mathrm{s}}$ of $3 \mathrm{Y}-\mathrm{TZP} 2$ feedstock is 0.81 that is prepared by $\Sigma$-blade kneader. That means $19 \%$ agglomerates are left in the feedstock. The result shows that the operation $170{ }^{\circ} \mathrm{C}$ shows the inputting power can break the less amounts about $5 \%$ of agglomera- tion. The $D_{\mathrm{s}}$ increases from 0.81 to 0.86 . The best operation among these three conditions is kneading at $150{ }^{\circ} \mathrm{C} / 30 \mathrm{rpm}$. The inputting power can improve $D_{\mathrm{s}}$ of the feedstock, and result in better homogeneity. The $D_{\mathrm{s}}$ increase quickly to 0.93. The efficiency of the input power of the conditions of $130{ }^{\circ} \mathrm{C}$ is the smallest. The $D_{\mathrm{s}}$ value raises from 0.81 to 0.82 . The final microstructures of these feedstocks are shown in Fig. 9.
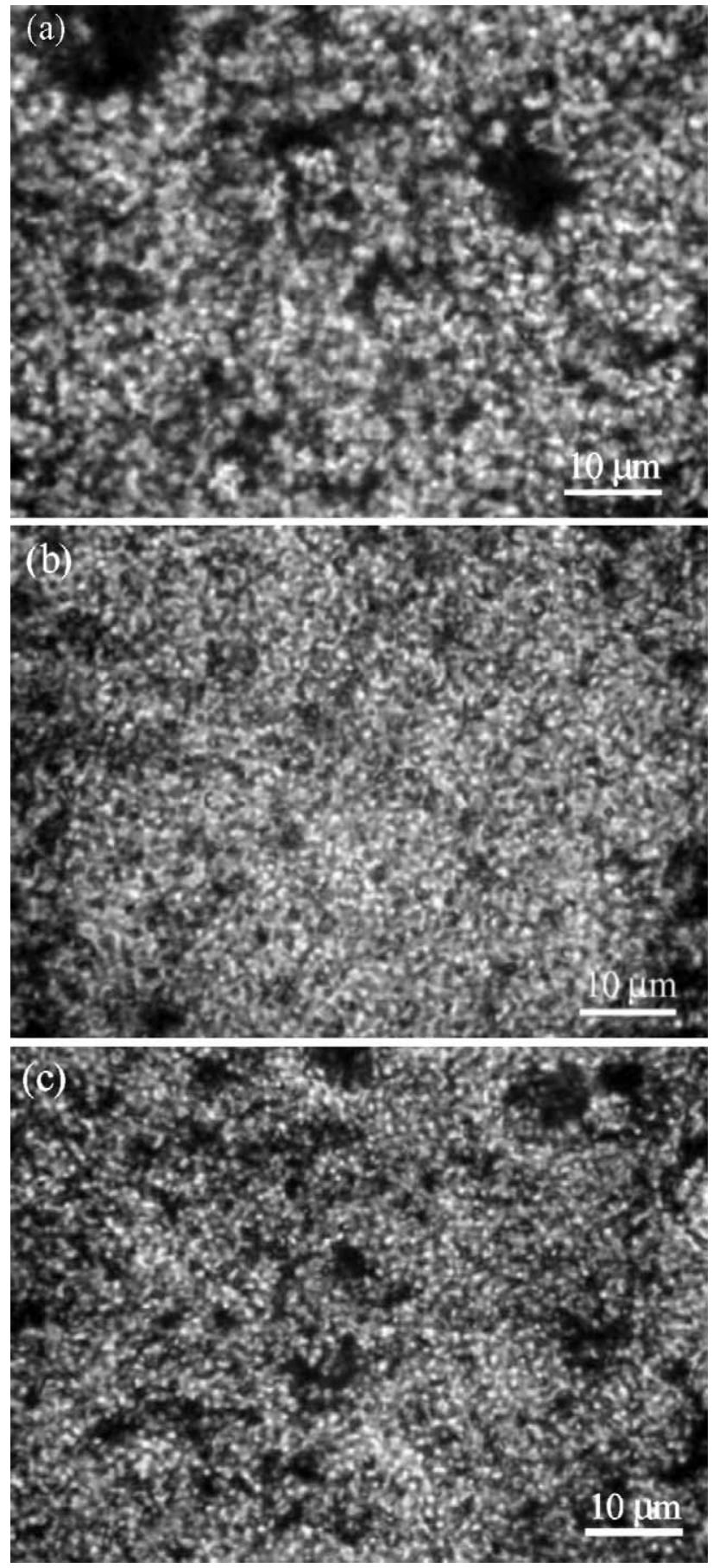

Fig. 9. OM morphologies of thin 3Y-TZP2 feedstock which was kneaded at (a) $130{ }^{\circ} \mathrm{C} / 21 \mathrm{rpm}$, (b) $150{ }^{\circ} \mathrm{C} / 30 \mathrm{rpm}$, or (c) $170^{\circ} \mathrm{C} / 55 \mathrm{rpm}$ for $60 \mathrm{~min}$. 


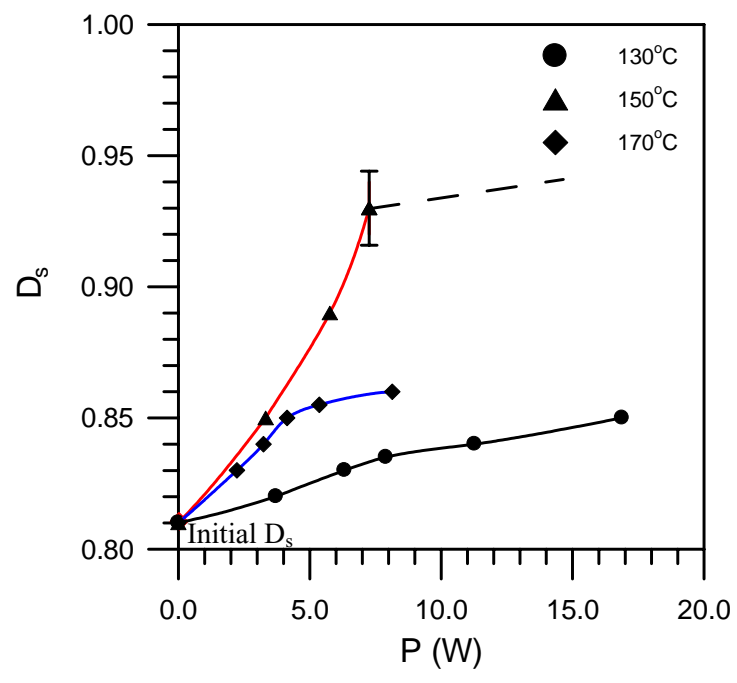

Fig. 10. Dispersive indexes as a function of power in various kneading conditions of 3Y-TZP, either kneading at 130,150 , and $170^{\circ} \mathrm{C}$ for $60 \mathrm{~min}$. The initial $D_{\mathrm{s}}(0.81)$ was prepared by $\Sigma$-blade kneader operated at $175^{\circ} \mathrm{C}$ for $120 \mathrm{~min}$.

The relationship between previous kneading conditions and dispersive index is summarized in Fig. 10. A lot of powder agglomerates are found in feedstock kneading at $130^{\circ} \mathrm{C}$ for $60 \mathrm{~min}$. The feedstock kneading at $170^{\circ} \mathrm{C}$ is more homogenous than $130^{\circ} \mathrm{C}$. The result implies that larger input power produced by higher blade speed $170{ }^{\circ} \mathrm{C}$ break down the powder agglomerate easily. The feedstock kneaded at lower blade speed of $130^{\circ} \mathrm{C}$ is difficult to break down powder agglomerate. Though the kneader produces larger torque at low temperature, the rate of interchange feedstock in the kneader vessels is lower. The result indicates that Reynolds number of feedstock play an important role to break down powder agglomerate in feedstock. The feedstock which kneaded at $150{ }^{\circ} \mathrm{C}$ shows the best improve the homogeneity, as shown in Fig. 10. The result shows that the kneading condition of $150^{\circ} \mathrm{C}$ can produce enough shear stress to break down agglomerate and the Reynolds number that kneaded feedstock can get much more rate of interchange. The opportunity that breaks down powder agglomerate increases with increasing rate of interchange. The feedstock kneaded in optimum condition, $150^{\circ} \mathrm{C} / 30 \mathrm{rpm}$, can be fabricated homogenously more than the others.

\section{Conclusion}

The rheological and torque behavior with respect to the homogeneity of zirconia feedstocks have been investigated. The homogeneity can be revealed by several quantitative index, including $\alpha_{\mathrm{stv}}, H_{\mathrm{a}}$ and $H_{\mathrm{z}}$, and show consistent results. However, the rheological behavior obtained by torque test and $D_{\mathrm{s}}$ (dispersive index) obtained by TOM clearly revealed the state of particle agglomeration and the microstructure of feedstocks.
The torque and related parameters used for the tests of the feedstocks were used to calculate power consumption of the kneader. The relationship between dispersive index and power from $N_{\mathrm{p}}{ }^{\prime}-R e^{\prime}$ diagram showed the critical operation conditions for the improvement of feedstock homogeneity. The results predict that the optimal power input at $150^{\circ} \mathrm{C} / 30 \mathrm{rpm}$ in association with other operation control can be used to greatly reduce the fraction of particle agglomeration in the feedstock.

\section{Acknowledgements}

The authors would like to thank the funding given by the Ministry of Education, ROC, base on the support of Excellent Center of nano-technology at NTU.

\section{References}

1. German, R. M. and Bose, A., Injection Molding of Metals and Ceramics, Powder Industries Federation, 1997.

2. Lin, S. T. P. and German, R. M., The influence of powder loading and binder additive on the properties of alumina injection-molding blends. J. Mater. Sci. 1994, 29, 5367-5373.

3. Zhang, T. and Evans, J. R. G., Predicting the viscosity of ceramic injection molding suspension. J. Eur. Ceram. Soc. 1989, 5, 165172.

4. Evans, A. G., Hasselman, D. P. H. and Lange, F. F. Fracture mechanics of ceramics. In Proceedings of the 3rd International Symposium on the Fracture Mechanics of Ceramics, Vol 5, 1983, pp. 789-792.

5. Michaeli, W., Rogalla, A. and Ziegmann, C., Mass-production of microstructures. Kunststoffe Plast. Eur. 1999, 89(9), 27-29.

6. Yano, T., Kongo to Seikei, Korin, Tokyo, Japan, 1990.

7. Okada, K., Akasaka, S., Akagi, Y. and Yoshioka, N., In Proceedings of the XIth International Congress on Rheology, Vol 1, Brussel, Beigium, 1992, pp. 425-529.

8. Nagata, S., Kagakukogaku Binran (3rd ed.). Maruzen, Tokyo, Japan, 1968, pp. 1103-1105.

9. Kamiwano, M., Kaminoyama, M. and Kawaguchi, Y., Measurement of uniformity of mixture of wet particulate system by electrochemical method. Sekiyu Gakkaishi 1995, 38, 311-317.

10. Nagata, S., Mixing, Kodansha Ltd., Tokyo, Japan, 1975, pp. 66-83.

11. Kamiwano, M., Kaminoyama, M., Nishi, K. and Suziki, Y., Power consumption diagram for wet particle kneader mixers-in the case that rheological properties for wet particles cannot be measured. J. Chem. Eng. Jpn. 2000, 33(3), 489-498.

12. Wu, R. Y. and Wei, W.-C. J., Torque evolution and effects on alumina feedstocks prepared by various kneading sequences. J. Eur. Ceram. Soc. 2000, 20, 65-67.

13. Wei, W.-C. J., Tsai, S. J. and Hsu, K. C., Effects of mixing sequence on alumina prepared by injection molding. J. Eur. Ceram. Soc. 1998, 18, 1445-1451.

14. Wei, W.-C. J. and Lin, W. J., Processing character of MgO-partially stabilized zirconia (PSZ) in size grading prepared by injection molding. J. Eur. Ceram. Soc. 1998, 18, 2107-2116.

15. Li, Y., Huang, B. and Qu, X., Viscosity and melt rheology of metal injection moulding feedstocks. Powder Metal. 1999, 42, 86-90.

16. Suetsugu, Y., The effect of mixing on some properties of compounds and composites. In Mixing and Compounding of Polymers: Theory and Practice, 1994, pp. 521-548.

17. Tomita, Y., Kikaikogaku Taikei 12-Rheology, Koronasha, Tokyo, Japan, 1975. 
18. Onogi, S., Mikami, Y. and Matsumoto, T., The rheology of suspension of titaniate fiber in polymer solution. Polymer Eng. Sci. 1977, 17, 1-8.

19. Metzner, A. B. and Otto, R. E., Agitation of non-Newtonian fluids. AIChE J. 1957, 3, 3-10.

20. Wu, R. Y. and Wei, W.-C., Effects of surfactant on Mg-PSZ feedstocks for powder injection molding. In The Fifth IUMRD International Conference on Advanced Materials, IUMRS-ICAM '99, China, 2000.
21. Song, J. H. and Evans, J. R. G., The injection moulding of fine and ultra-fine zirconia powders. Ceram. Int. 1995, 21, 325-333.

22. Trunec, M., Dobsak, P. and Cihlar, J., Effect of powder treatment on injection moulded zirconia ceramics. J. Eur. Ceram. Soc. 2000, 20 859-866.

23. Rushton, J. H., Costich, E. W. and Everett, H. J., Power characteristics of mixing impellers. Part I. Chem. Eng. Prog. 1950, 46, 395. 